Samira Pirola Santos MANTILLA ${ }^{1}$

Robson Maia FRANCO'

Luiz Antônio Trindade de OLIVEIRA ${ }^{1}$

Érica Barbosa SANTOS ${ }^{1}$

Raquel GOUVÊA ${ }^{1}$

\section{Correspondência para:}

Samira Pirola Santos Mantilla

Rua Maurício Lage, lote 12, quadra 41

Bairro Itaipu Cep: 24346-090 - Niterói,RJ.

e-mail: samiramantilla@yahoo.com.br

Recebido para publicação em 17/10/2006 Aprovado para publicação em 13/12/2007

\title{
Resistência antimicrobiana de bactérias do gênero Listeria spp. isoladas de carne moída bovina
}

\author{
1 - Universidade Federal Fluminense, Niterói-RJ
}

\section{Resumo}

Com o aumento do uso de antimicrobianos como promotores de crescimento e até mesmo com fins terapêuticos na criação de animais de produção, existe o interesse global referente ao consumo de baixos níveis de resíduos de antimicrobianos em alimentos e os efeitos destes na saúde humana. A ingestão de alimentos contendo resíduos de fármacos antimicrobianos pode ocasionar resistência bacteriana aos antimicrobianos utilizados rotineiramente na terapêutica humana, dificultando o tratamento de enfermidades infecciosas humanas. Neste experimento foi realizado o teste de sensibilidade aos antimicrobianos em cepas de Listeria spp. isoladas a partir de amostras de carnes bovinas, através da metodologia descrita pelo NCCLS em 2003. De acordo com os resultados, todas as cepas isoladas foram resistentes à maioria dos antimicrobianos testados. As cepas de L. monocytogenes foram resistentes à gentamicina, cefoxitina, ampicilina, clindamicina, oxaciclina e sulfazotrim. As cepas de L. innocua isoladas foram resitentes à gentamicina, cefoxitina, tetraciclina, vancomicina, oxaciclina e clindamicina.

\section{Introdução}

A utilização de antimicrobianos gerou grande otimismo em relação à prevenção e ao tratamento dos processos infecciosos. Entretanto, o uso exagerado e nem sempre criterioso ou racional dos antimicrobianos e quimioterápicos trouxe dificuldades, sendo a maior delas representada pela progressiva resistência bacteriana aos fármacos. ${ }^{1}$

As bactérias podem ser classificadas em sensíveis e resistentes aos antimicrobianos. Em geral, classificam-se como resistentes, as bactérias que crescem "in vitro", nas concentrações médias que os antimicrobianos atingem no sangue, quando administrados por via oral. São sensíveis as que não crescem nestas concentrações. ${ }^{2}$

De acordo com Trabulsi e Toledo ${ }^{2}$, a resistência bacteriana pode ser natural ou adquirida. A natural corresponde a uma característica da espécie bacteriana, e a adquirida, à característica de uma ou mais amostras da espécie. A aquisição de resistência por uma célula bacteriana sensível é sempre decorrente de uma alteração genética.

O gênero Listeria apresenta uma susceptibilidade uniforme aos antimicrobianos contra bactérias Gram positivas. ${ }^{3}$ Os antimicrobianos mais indicados no tratamento da listeriose são : tetraciclina, coumercina, rifampicina, cloranfenicol, eritromicina e ampicilina, sendo esta última adicionada de um antibiótico aminoglicosídio. ${ }^{4,5}$ Marth $^{6}$ relata que a maioria das cepas é sensível à tetraciclina, cloranfenicol, eritromicina e cefalotina. Ampicilina, rifampicina, ou penicilina associada com gentamicina são os antimicrobianos de escolha para o tratamento de listeriose. ${ }^{7}$ A associação de trimetoprim com uma sulfonamida como a sulfametoxazole no co-trimoxazole, é considerada como uma segunda opção para o tratamento. ${ }^{8}$ Para o tratamento da bacteremia e da mulher grávida com listeriose, utiliza-se a vancomicina e a eritromicina, respectivamente. ${ }^{7}$

Mesmo com o uso destes fármacos, a terapia com antimicrobianos para listeriose 
não é inteiramente satisfatória, uma vez que pacientes doentes e hospedeiros comprometidos são mais difíceis de tratar do que hospedeiros sadios. ${ }^{5}$

Hansen et al. ${ }^{9}$ examinaram a susceptibilidade aos antimicrobianos de cepas de L. monocytogenes isoladas de pacientes em Denmark. As cepas foram sensíveis a todos os antimicrobianos testados incluindo penicilina, ampicilina e sulfametoxazole, com exceção a ciprofloxacina cujas cepas demonstraram sensibilidade moderada.

As espécies de Listeria isoladas por Yucel, Citake e Onder ${ }^{10}$ oriundas de amostras de carne bovina e produtos cárneos, demonstraram resistência a cefalotina, ampicilina e ácido nalidíxico, porém, exibiram um grande grau de susceptibilidade a canamicina, cloranfenicol e tetraciclina.

Na pesquisa realizada por Gonçalves ${ }^{11}$, isolaram-se cepas de Listeria spp., provenientes de amostras de frango congeladas, resistentes a tetraciclina, cloranfenicol, eritromicina e ampicilina. Além disso, todas as 246 cepas demonstraram resistência aos antimicrobianos cefoxitina, cefalexina, ceftadizima e cefolaxima.

Antunes et al. ${ }^{12}$ observaram altas percentagens de Listeria spp. (84\%) e L. monocytogenes $(74 \%)$ isoladas de carcaças de frango resistentes a um ou mais agentes antimicrobianos. Ainda neste trabalho, a resistência da $L$. monocytogenes a enrofloxacina e a clindamicina foi notada.

De acordo com o resultado obtido por Araújo ${ }^{13}$, todas as 52 cepas de $L$. monocytogenes isoladas de amostras de "blanquet" de presunto de peru fatiados também se mostraram resistentes aos antimicrobianos ceftadizina, cefalexina e cefoxitina. Algumas cepas demonstraram resistência a cefalotina, clindamicina, amicacina, ceftriaxona e cefotaxima.

No trabalho realizado por Kasnowski ${ }^{14}$ das 16 cepas de L. monocytogenes $4 \mathrm{~b}$ isoladas de carne bovina, cinco foram sensíveis a teicoplamina, sete a vancomicina e três intermediárias a clindamicina. A cepa de Listeria innocua rugosa isolada demonstrou resistência a todos antibióticos testados. Ocorreu a presença de uma cepa de sensibilidade intermediária a ceftriaxona, uma sensível a cefalotina, três sensíveis a gentamicina e duas sensíveis a tetraciclina; correspondentes aos sorovares de Listeria innocua. Todas as cepas analisadas apresentaram resistência a penicilina, a oxacilina, a eritromicina, a ampicilina e a cefoxitina.

Aureli et al. ${ }^{3}$ observaram durante o experimento, que todas as cepas de $L$. monocytogenes isoladas a partir de diversos alimentos foram sensíveis aos antimicrobianos testados, com exceção para fosfomicina, lincomicina e flumequine para os quais as cepas demonstraram resistência. As estirpes apresentaram sensibilidade moderada para somente quatro antimicrobianos: espiramicina (salmão, leite, carne de ave), cloranfenicol (carne de ave e bovina), tetraciclina (carne bovina) e sensibilidade marginal a estreptomicina (carne de ave).

$\mathrm{Na}$ pesquisa desenvolvida por Prazak et al. ${ }^{15}, 21$ isolados de L. monoctogenes oriundos de amostras de repolho, do meio ambiente e de água foram testados com relação à resistência antimicrobiana. Dos isolados testados, 95\% foram resistentes a dois ou mais antimicrobianos; $85 \%$ das cepas multiresistentes foram resistentes a penicilina. A cepa multiresistente que demonstrou sensibilidade intermediária à penicilina foi resistente a gentamicina.

O objetivo deste estudo foi avaliar a sensibilidade antimicrobiana das espécies de listerias isoladas a partir de amostras de carne moída bovina, obtidas em diferentes estabelecimentos comerciais no município de Niterói, RJ.

\section{Material e Método}

Vinte e quatro cepas de Listeria spp., isoladas de carne moída bovina, através da metodologia revisada do "USDA-FSIS" 16, foram testadas, segundo a metodologia do "Clinical and Laboratory Standards Institute" 17 , para avaliar a sensibilidade 
aos seguintes antimicrobianos: clindamicina, oxaciclina, gentamicina, sulfazotrim, cefoxitina, ampicilina, ciprofloxacina, rifampicina, cloranfenicol, amicacina, vancomicina, tetraciclina, penicilina, cefalotina e eritromicina. Destas vinte e quatro cepas, seis pertenciam a espécie L. monocytogenes, quatro eram L. innocua não tipável, sete eram cepas de L. innocua 6 b e sete eram de L. innocua 6 a.

As cepas isoladas, biotipificadas e sorotipadas, em estoque, foram mantidas em meio ambiente durante 30 minutos, sendo, após este tempo semeadas em agar tripticase de soja com $0,6 \%$ de extrato de levedura e incubadas a $30^{\circ} \mathrm{C}$ por 24 horas. Os subcultivos crescidos foram homogeneizados em água destilada esterilizada, padronizando-se a suspensão para uma turvação igual ao padrão número um da escala de Mc Farland: 1 $\mathrm{mL}$ de cloreto de bário $\left(\mathrm{BaCl}_{2}\right)$ a $1 \%+$ $99 \mathrm{~mL}$ de ácido sulfúrico $\left(\mathrm{H}_{2} \mathrm{SO}_{4}\right)$ a $1 \%$ $(0,36 \mathrm{~N})$ que corresponde a $3,8 \times 10^{8}$ microrganismos por mililitro. Placas contendo ágar Müeller Hinton, após serem retiradas da geladeira, incubadas a $37^{\circ} \mathrm{C}$ durante 1 hora antes da semeadura e mantidas em temperatura ambiente por 3 a 5 horas, foram semeadas utilizando-se um "swab" esterilizado embebido com o inóculo, sendo espalhado homogeneamente na superfície do meio.

Após alguns minutos para a absorção do inóculo, foram colocados os polisensidiscos 15 (série Gram-positivo) da marca DME com auxílio de uma pinça previamente flambada e resfriada. As placas foram incubadas a $30^{\circ} \mathrm{C}$ durante 24 horas.

O resultado foi determinado a partir da mensuração do tamanho da zona de inibição com um halômetro e na classificação das cepas em sensíveis, moderadamente sensíveis, intermediárias ou resistentes de acordo com o diâmetro da zona padrão estabelecida na tabela para cada antimicrobiano.

\section{Resultados e Discussão}

A resistência bacteriana aos antimicrobianos é um tema amplamente pesquisado por diversos autores, devido a grande importância desta condição para a saúde pública. À medida que os antimicrobianos vão sendo utilizados indiscriminadamente, aumenta-se o número de bactérias resistentes às drogas mais utilizadas na terapia humana. Todas as cepas de L. monocytogenes isoladas nesta pesquisa apresentaram-se resistentes aos antimicrobianos: clindamicina, oxaciclina, gentamicina, sulfazotrim, cefoxitina e inclusive a ampicilina, que é uma das drogas mais indicadas para o tratamento da listeriose segundo $\mathrm{Jay}^{5}$ e Castro ${ }^{4}$. Os resultados obtidos neste experimento podem ser observados na tabela 1 e figura 1.

Da mesma forma, Gonçalves ${ }^{11}$ isolou cepas de Listeria spp. resistentes a tetraciclina, cloranfenicol, eritromicina, ampicilina e cefoxitina a partir de cortes de frango congelados.

Araújo ${ }^{13}$ também descreveu cepas de L. monocytogenes resistentes aos antimicrobianos cefoxitina, cefalotina, clindamicina e amicacina. Yucel, Citaka e Ander ${ }^{10}$ isolaram espécies de Listeria, oriundas de carne bovina e produtos cárneos, resistentes a ampicilina e cefalotina. Da mesma forma, Kasnowski ${ }^{14}$ relatou que todas as cepas de L. monocytogenes isoladas a partir de amostras de carne bovina apresentaram resistência à penicilina, à oxacilina, à eritromicina, à ampicilina e à cefoxitina.

Também se encontrou neste trabalho cepas desta mesma espécie resistentes a outros antibióticos indicados no tratamento da listeriose humana, como por exemplo, tetraciclina e cefalotina, aos quais $66,7 \%$ das cepas demonstraram resistência, e eritromicina, onde 83,3\% apresentaram-se resistentes. Na tabela 1 e figura 1 constam estes valores. Estes resultados confrontam com os citados por Marth ${ }^{6}$ o qual relata que a maioria das cepas de L. monocytogenes é sensível a estes antimicrobianos. 
Tabela 1 - Comportamento das seis cepas de L. monocytogenes isoladas frente aos antimicrobianos testados. Niterói - RJ, 2006

\begin{tabular}{|c|c|c|c|c|c|c|}
\hline Antimicrobiano & $\begin{array}{c}\mathbf{N}^{\circ} \text { de } \\
\text { cepas } R\end{array}$ & $(\%)$ & $\begin{array}{c}N^{\circ} \text { de } \\
\text { cepas I }\end{array}$ & $(\%)$ & $\begin{array}{c}\mathrm{N}^{\circ} \text { de } \\
\text { cepas } \mathrm{S}\end{array}$ & $(\%)$ \\
\hline Gentamicina & 6 & 100 & 0 & 0 & 0 & 0 \\
\hline Ampicilina & 6 & 100 & 0 & 0 & 0 & 0 \\
\hline Cefoxitina & 6 & 100 & 0 & 0 & 0 & 0 \\
\hline Clindamicina & 6 & 100 & 0 & 0 & 0 & 0 \\
\hline Oxaciclina & 6 & 100 & 0 & 0 & 0 & 0 \\
\hline Sulfazotrim & 6 & 100 & 0 & 0 & 0 & 0 \\
\hline Eritromicina & 5 & 83,3 & 0 & 0 & 1 & 16,7 \\
\hline Tetraciclina & 4 & 66,7 & 0 & 0 & 2 & 33,3 \\
\hline Penicilina & 4 & 66,7 & 0 & 0 & 2 & 33,3 \\
\hline Cefalotina & 4 & 66,7 & 0 & 0 & 2 & 33,3 \\
\hline Ciprofloxacina & 4 & 66,7 & 1 & 16,7 & 1 & 16,7 \\
\hline Amicacina & 3 & 50 & 0 & 0 & 3 & 50 \\
\hline Vancomicina & 3 & 50 & 0 & 0 & 3 & 50 \\
\hline Cloranfenicol & 3 & 50 & 1 & 16,7 & 2 & 33,3 \\
\hline Rifampicina & 3 & 50 & 1 & 16,7 & 2 & 33,3 \\
\hline
\end{tabular}

Onde: $\mathrm{R}=$ resistentes $/ \mathrm{I}=$ intermediárias $/ \mathrm{S}=$ sensíveis

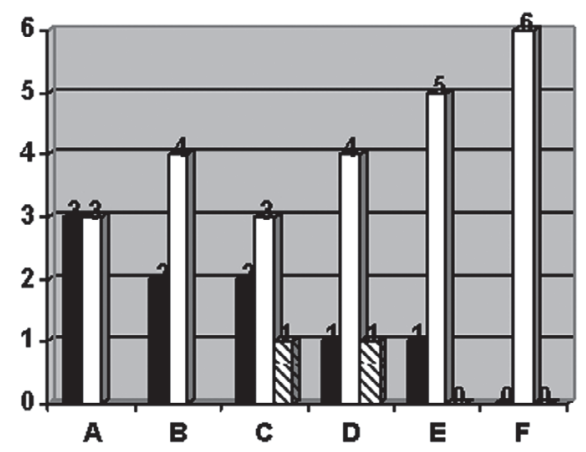

A - amicacina e vancomicina

B - tetraciclina, penicilina e cefalotina

C - cloranfenicol e rifampicina

D - ciprofloxacina

E - eritromicina

F- gentamicina, cefoxitina, ampicilina,

clindamicina, oxaciclina, sulfazotrim

Gensivel $\square$ Resistente $\mathbf{Q}$ Intermediária

Figura 1 - Cepas de L. monocytogenes sensíveis, intermediárias e resistentes aos antimicrobianos testados (ao total foram seis cepas)

$\mathrm{Jay}^{5}$ ainda ressalta a rifampicina como fármaco de escolha para o tratamento, porém, no presente estudo, $50 \%$ das cepas isoladas foram resistentes a este antimicrobiano.

Em relação à penicilina, 66,7 \% das cepas de $L$. monocytogenes demonstraram-se resistentes a este antibótico, entretanto, os resultados obtidos por Hansen et al. ${ }^{9}$ confrontam com os obtidos neste experimento, pois estes pesquisadores observaram que todas as cepas de $L$. monocytogenes isoladas a partir de pacientes, foram sensíveis a penicilina e a ampicilina.

Todas as cepas $(100 \%$ dos isolados testados) foram resistentes a dois ou mais antimicrobianos, sendo que $66,7 \%$ destas cepas multiresistentes apresentaram resistência a penicilina. Prazak et al. ${ }^{15}$ encontraram resultados muito parecidos, onde $95 \%$ das cepas de L. monocytogenes oriundas de amostras de repolho, do meio ambiente e de água foram resistentes a dois ou mais antimicrobianos, e $85 \%$ destas demonstraram resistência à penicilina. Antunes et al. ${ }^{12}$ também isolaram cepas de L. monocytogenes, a partir de carcaças de frango, com múltipla resistência antimicrobiana em $74 \%$ das amostras analisadas.

As cepas de $L$ innocua isoladas também foram resistentes à maioria dos antimicrobianos testados. $\mathrm{O}$ comportamento das cepas de L innocua 6 a, 6 b e não tipável frente aos antimicrobianos testados pode ser observado na tabela 2 . 
Tabela 2 - Comportamento das cepas de L. innocua 6a, L. innocua 6b e L. innocua não tipáveis isoladas, frente aos antimicrobianos testados. Niterói - RJ, 2006

Cepas resistentes

\begin{tabular}{|c|c|c|c|c|c|c|}
\hline \multirow[t]{2}{*}{ Antimicrobiano } & \multicolumn{2}{|c|}{$\begin{array}{c}7 \text { cepas de } L \text {. innocua } \\
6 \mathrm{a}\end{array}$} & \multicolumn{2}{|c|}{$\begin{array}{c}7 \text { cepas de } L \text {. innocua } \\
6 \mathrm{~b}\end{array}$} & \multicolumn{2}{|c|}{$\begin{array}{c}4 \text { cepas de } L \text {. innocua } \\
\text { não tipáveis }\end{array}$} \\
\hline & $\mathbf{N}^{\circ}$ & $\%$ & $\mathbf{N}^{\circ}$ & $\%$ & $\mathbf{N}^{\circ}$ & $\%$ \\
\hline Amicacina & 5 & 71,4 & 0 & 0 & 2 & 50 \\
\hline Vancomicina & 7 & 100 & 7 & 100 & 3 & 75 \\
\hline Cloranfenicol & 4 & 57,1 & 5 & 71,4 & 3 & 75 \\
\hline Tetraciclina & 6 & 85,7 & 7 & 100 & 3 & 75 \\
\hline Rifampicina & 6 & 85,7 & 6 & 85,7 & 3 & 75 \\
\hline Penicilina & 4 & 57,1 & 3 & 42,9 & 1 & 25 \\
\hline Cefalotina & 3 & 42,9 & 5 & 71,4 & 1 & 25 \\
\hline Ciprofloxacina & 5 & 71,4 & 3 & 42,9 & 1 & 25 \\
\hline Eritromicina & 4 & 57,1 & 5 & 71,4 & 0 & 0 \\
\hline Gentamicina & 6 & 85,7 & 7 & 100 & 0 & 0 \\
\hline Ampicilina & 3 & 42,9 & 3 & 42,9 & 3 & 75 \\
\hline Cefoxitina & 5 & 71,4 & 7 & 100 & 3 & 75 \\
\hline Clindamicina & 6 & 85,7 & 5 & 71,4 & 4 & 100 \\
\hline Oxaciclina & 7 & 100 & 5 & 71,4 & 2 & 50 \\
\hline Sulfazotrim & 6 & 85,7 & 6 & 85,7 & 3 & 75 \\
\hline
\end{tabular}

Conclusões

A existência de cepas de L. monocytogenes resistentes aos antimicrobianos utilizados rotineiramente no tratamento da listeriose humana representa um problema para a saúde coletiva, principalmente para os indivíduos que fazem parte do grupo de risco da listeriose, que incluem os idosos, crianças, mulheres grávida e imunossuprimidos.
Os antimicrobianos nunca podem ser usados como uma alternativa fácil para obtenção de boas práticas na criação e produção de animais de açougue. Governos nacionais necessitam propor um programa de controle de resíduos de antimicrobianos na produção animal, que vise controlar a aprovação ou licenciamento de antimicrobianos e controlar a venda e o uso em propriedades rurais.

\section{Antibiotic sensitivity of bacterias of the genus Listeria spp. isolated from bovine ground meat samples}

\begin{abstract}
With the increasing use of antibiotics as growth promoters and even for therapeutical purposes on breeding of food-producing animals, there is the worldwide interest related to the ingestion of antibiotical residues on food and their effects on human health. The ingestion of food containing antibodies residues can cause bacterial resistence to the antibodies usually used on human therapies, what difficult the treatment of human infectious illnesses. Antibiotic sensitivity test was realized on Listeria spp. Strains, which were isolated from bovine meat samples, according to the National Committee for Clinical Laboratory Standards (NCCLS), 2003. According to the finding results, all isolated strains showed resistance to gentamicine, cefoxitine, ampicyline, clindamicine, oxacycline and sulfazotrim. L. innocua isolated strains showed resistance to gentamicine, cefoxitine, tetracycline, vancomicine, oxacycline and clindamicine.
\end{abstract}

Key words: Antibiotics. Food. Listeriosis. 


\section{Referências}

1 MONTELLI. A. C.; SADATSUNE, T. Antibioticoterapia para o clínico. Rio de Janeiro: Sociedade Brasileira de Microbiologia, 2001. p. 7-53.

2 TRABULSI, L. R.; TOLEDO, M. R. F. Resistência Bacteriana a Droga. In: TRABULSI, L. R. Microbiologia. 2. ed. São Paulo: Atheneu, 1989. cap. 13, p. 86-89.

3 AURELI, P. et al. Susceptibility of Listeria monocytogenes isolated from food in Italy to antibiotics. International Journal of Food Microbiology, v. 83, p. 325-330, 2003

4 CASTRO, A. F. P. Listeria. In: TRABULSI, L. R. Microbiologia. 2. ed. São Paulo: Atheneu, 1989. cap. 26, p. 131-132.

5 JAY, J. M. Listerioses de origem animal. In: JAY, J. M. Microbiologia de alimentos. 6 ed. Porto Alegre: Artmed, 2005. cap. 25, p. 517-542.

6 MARTH, E. H. Disease characteristic of Listeria monocytogenes. Food Technology, v. 42, n. 51, p. 165168, 1988.

7 WHITE, O. G. et al. Antimicrobial resistance of foodborne pathogens. Microbes and Infection, v. 4, p. 405-412, 2002

8 CHARPENTIER, E.; COURVAÇIN, P. Minireview. Antibiotic Resistence in Listeria spp. Antimicrobial Agents and Chemotherapy, v. 43, n. 9, p. 2103-2108, 1999.

9 HANSEN, J. M. et al. Antibiotic susceptibility of Listeria monocytogenes in Denmark 1958-2001. APMIS, v. 113, p. 31-36, 2005.

10 YUCEL, N.; CITAK, S.; ONDER, M. Prevalence and antibiotic resistance of Listeria species in meat products in Ankara, Turkey. Food Microbiology, v. 22, p. 2-3, 2005.

11 GONÇALVES, P. M. R. Isolamento e identificação de Listeria spp. a partir de amostras de cortes de peito de frango congelados: avaliação de metodologias e fatores interferentes. 1998. 111 f. Dissertação (Mestrado em Higiene Veterinária e Processamento Tecnológico de Produtos de Origem Animal) - Universidade Federal Fluminense, Niterói, RJ, 1998.

12 ANTUNES, P. et al. Incidence and susceptibility to antimicrobial agents of Listeria spp. and Listeria monocytogenes isolated from poultry carcasses in Porto, Portugal. Journal of Food Protection, v. 65, n. 12, p. 1888-1893, 2002.

13 ARAÚJO, P. C. C. Listeria monocytogenes: ocorrência, verificação da eficiência de dois meios de plaqueamento, sorovares predominantes e sensibilidade aos antimicrobianos de cepas isoladas em produtos de carne de peru comercializados na cidade de Niterói-RJBrasil. 1998. 90 f. Dissertação (Mestrado em Medicina Veterinária) - Universidade Federal Fluminense, Niterói, RJ, 1998.

14 KASNOWSKI, M. C. Listeria spp., Escherichia coli: isolamento, identificação, estudo sorológico e antimicrobiano em corte de carne bovina (alcatra) inteira e moída. 2004. 110 f. Dissertação (Mestrado em Higiene Veterinária e Processamento Tecnológico de Produtos de Origem Animal) - Universidade Federal Fluminense, Niterói, RJ, 2004.

15 PRAZAK, M. A. et al. Antimicrobial resistence of Listeria monocytogenes isolated from various cabbage farms and packing sheds in Texas. Journal of Food Protection, v. 65, n. 11, p. 1796-1799, 2002.

16 MCCLAIN, D.; LEE, W. H. Development of USDAFSIS method for isolation of Listeria monocytogenes from raw meat and poultry. 4. ed. Virginia: Food and Drug Administration, 1984. p. 6 -11.

17 CLINICAL AND LABORATORY STANDARDS INSTITUTE, NCCLS. Performance standards for antimicrobial susceptibility testing. Pensylvania: Clinical and Laboratory Standards Institute, 2005. 15 Informational Supplement. CLSI/ NCCLS document M100-515. 